\title{
СОВРЕМЕННЫЕ ПОДХОДЫ К ОРГАНИЗАЦИОННОМУ ОБУЧЕНИЮ: КОРПОРАТИВНАЯ МОДЕЛЬ МЕДИАОБРАЗОВАНИЯ
}

\section{CORPORATE MODEL OF MEDIA EDUCATION: OPPORTUNITIES AND PERSPECTIVES}

V. Yarnykh

Summary: The expansion of the online space has significantly changed the organizational reality of the company. In this regard, all management systems, including the corporate education system, are undergoing significant changes. The emergence of new generations of employees on the labor market, the expansion of the media reality of the company, and a significant change in business processes require new approaches to the system of organizational education as a whole. The situation with the COVID-19 pandemic, which turned into an infodemia, showed the need to develop new media, information and digital competencies among employees, and in general, the need to develop and implement a corporate media education model. The article presents new approaches to the formation of a media education model, a factor that affects its development and implementation.

Keywords: media education, corporate model of media education, organizational learning, theory of generations, principles of corporate education, media and information literacy, digital literacy.
$\mathrm{P}$ асширение онлайн пространства существенно изменили организационную реальность компании. В связи с этим значительные изменения претерпевают все управленческие системы, в том числе и корпоративная система образования. Появление на рынке труда новых поколений сотрудников, расширение медийной реальности компании, существенное изменение бизнес-процессов требуют и новых подходов к системе организационного образования в целом.

Ситуация весны - лета 2020 года не просто внесла существенные коррективы в сложившуюся ситуацию, но и заставила пересмотреть сам подход к пониманию корпоративного обучения в целом. Понадобились новые подходы и новые инструменты развития медийной и информационной, цифровой грамотности, а также новые компетенции взаимодействия сотрудников компании в цифровой среде.

Прежде всего, необходимо отметить произошедшие изменения в самой бизнес-среде. Ситуация пандемии высветила несколько факторов, которые оказали существенное влияние на изменение подходов к системе корпоративного образования.

\author{
Ярных Вероника Игоревна \\ К.э.н., дочент, Российский Государственный \\ Гуманитарный Университет, Москва \\ vyarnykh@gmail.com
}

Аннотация: Расширение онлайн пространства существенно изменили организационную реальность компании. В связи сэтим значительные изменения претерпевают все управленческие системы, в том числе и корпоративная система образования. Появление на рынке труда новых поколений сотрудников, расширение медийной реальности компании, существенное изменение бизнес-процессов требуют и новых подходов к системе организационного образования в целом, а также использование новых образовательных инструментов в частности. Ситуация с COVID-19 пандемией, которая превратилась в инфодемию показала необходимость развития новых медийно-информационных и цифровых компетенций у сотрудников, и в целом необходимость разработки и внедрения корпоративной модели медиаобразования. В статье представлены новые подходы к формированию модели медиаобразования, фактор, которые влияют на ее развитие и внедрение.

Ключевые слова: медиаобразование, корпоративная модель медиаобразования, организационное образование, теория поколений, принципы корпоративного образования, медийная и информационная грамотность, цифровая грамотность.

Наиболее важным фактором стало существенное расширение корпоративного онлайн пространства. Ситуация локдауна во всем мире заставила компании перейти не просто в онлайн и дистанционную работу. Такой экстренный переход показал не просто неготовность как таковую работать в другом формате. Онлайн формат работы или дистанционное взаимодействие требует наличия с одной стороны опыта, с другой стороны соответствующих компетенций. Как отмечают Конобевцев и др. [9, с. 11] компетенции для дистанционной работы требуют прежде всего совсем других технологий коммуникаций. Причем необходимо отметить как коммуникации внутри организации, так и во вне. Более того корпоративные коммуникации становятся глобальными, затрагивая расширенное число заинтересованных сторон.

Вторым важным фактором влияния становится изменение бизнес-процессов организации. Это не просто перевод бизнес - процессов в электронный вид, и конечно же не просто цифровизация бизнес-процессов как таковая. Не все бизнес-процессы в принципе можно перевести в цифровой вид [8]. Как было отмечено Андреем Ивановым, компания «Крок», не все компании оказались готовы к переходу на дистанционную работу. Прежде 
всего трудности возникли у тех компаний и организаций, которые не относятся к ИТ - сфере [8]. Два фактора в целом усложнили переход сотрудников на дистанционный режим работы. На первом месте, как выяснилось, оказалось материально - техническое обеспечение. Как отмечали многие эксперты, при использовании домашних гаджетов часто технические возможности не совпадали с требуемыми для работы в бизнес - процессах. Это относится и к программному обеспечению, и к чисто техническим возможностям. Такая проблема наблюдалась предыдущие насколько лет в крупных корпорациях при развитии элементов мобильного обучения [8]. Приходится отметить, что на втором месте по сложностям оказалось отсутствие привычки работать в дистанционном формате в принципе. В выигрыше оказались те компании, которые и до локдауна практиковали именно дистанционный формат работы. Несколько дней командировок, работа в отпуске и т.д. не стала такой практикой, к сожалению. Наоборот, такой опыт сформировал внутри компании завышенные ожидания и не показал необходимого результата.

Еще одним фактором влияния, конечно же, становятся вопросы цифровой грамотности для сотрудников. Этот фактор, по сути, вытекает из первых двух. Цифровая грамотность - это компетентность сотрудников в области использования программного обеспечения и умение работать в цифровой среде. Именно с этим возникали проблемы у многих компаний, причем не только в Российской Федерации, но и в Европе.

Выяснилось, что сотрудники компании замечательно освоили Instagram, чтобы размещать селфи, но при этом совершенно не умеют работать в экосистеме Google, например. Работа с Zoom, другими ресурсами для видеосвязи и коммуникаций оказались не знакомы для подавляющего большинства сотрудников компаний и потребовали от компаний существенных форсмажорных усилий по организации обучающих курсов.

Внутренние ресурсы для работы в системе онлайн или в условиях удаленной работы также, по сути, оказались неизвестны большинству сотрудников. Такой одномоментный переход в систему удаленного доступа выявил множество организационных проблем, и цифровая грамотность сотрудников оказалась не последней в списке. Без дополнительного обучения людей бизнеспроцессы, по сути, затормозились. Еще одним важным фактором стало использование теневых сервисов и неавторизованного программного обеспечения. Практика компаний, у которых не было предыдущего опыта работы в дистанционном формате, показала, что имеющиеся корпоративные приложения и корпоративные ресурсы неудобны для удаленного доступа. Важным фактором неэффективности стала внутренняя неготовность сотрудников компании согласовывать документы, мнения, вести документооборот в цифровом виде. Это оказалось неудобно, непривычно, некомфортно. Многие компании и крупного, и среднего бизнеса были вынуждены буквально «на ходу» перестраивать политики и процедуры.

При этом согласно опросу Gartner, результаты которого были опубликованы в начале апреля 2020 года, 74\% опрошенных организаций на тот момент планировали и дальше оставить сотрудников на удаленном формате работы. Это заявила компания Russia Today (RT) например. Также опрос продемонстрировал готовность 17\% опрошенных компаний сохранить в удаленном формате работы до 20\% своего штата. В 4\% опрошенных организаций заявили, что в удаленном формате продолжит работать половина сотрудников, которые были переведены на такой формат вынужденно, а еще в $2 \%$ планируют оставить в новом режиме более половины переведенных сотрудников по окончании пандемии[10].

При этом согласно опросу Gartner, результаты которого были опубликованы в начале апреля 2020 года, 74\% опрошенных организаций на тот момент планировали и дальше оставить сотрудников на удаленном формате работы. Это заявила компания Russia Today (RT) например. Также опрос продемонстрировал готовность 17\% опрошенных компаний сохранить в удаленном формате работы до 20\% своего штата. В 4\% опрошенных организаций заявили, что в удаленном формате продолжит работать половина сотрудников, которые были переведены на такой формат вынужденно, а еще в $2 \%$ планируют оставить в новом режиме более половины переведенных сотрудников по окончании пандемии[10].

В этих условиях и с учетом заявленных планов цифровая грамотность сотрудников компаний приобретает значимое влияние на результативность и эффективность работы компании. Важно отметить, что не смотря на длительность исследований не существует пока согласованной позиции в научном сообществе относительно точности формулировок понятий «медийно -информационная грамотность» и «цифровая грамотность». В контексте предложенной корпоративной модели медиаобразования предпочтительными являются следующие определения и понятия. В данном контексте наиболее точным и потенциальным выглядит определение медийно - информационной грамотности, предложенное ЮНЕСКО. ЮНЕСКО предложило следующую формулировку, основанную на междисциплинарном подходе. В ней указывается, что «... медийно-информационная грамотность - это совокупность знаний, навыков, установок, компетенций и практик, которые позволяют обеспечить эффективный доступ, анализ, критическую оценку, интерпретацию, использование, создание и распространение информации и медийных продуктов с использованием всех необходимых средств и инструментов на творческой, законной и этичной основе»[4]. 
В этом же контексте формулировка цифровой грамотности следующая: «цифровая грамотность - это способность человека использовать цифровые инструменты (в самом широком смысле) с пользой для себя. ... Цифровая грамотность включает личностные, технические и интеллектуальные навыки, которые необходимы для того, чтобы жить в цифровом мире» [1, с. 35].

Таким образом, в условиях современной инфодемии с одной стороны, и развития дистанционной работы и онлайн бизнеса с другой необходимость изменения корпоративной модели обучения в целом, и изменение или даже введение корпоративной модели медиаобразования в частности существенно выросла.

Говоря о новых подходах к формированию системы корпоративного образования, и, главное, о корпоративной модели медиаобразования важно отметить следующие моменты. Прежде всего современная система корпоративного образования претерпевает существенные изменения не только в связи с локдауном или пандемией COVID-19. Прежде всего требованием к изменению системы корпоративного образования в целом стало изменение структуры рынка труда и появление практически трех очень разных поколений X,Y,Z. Этот фактор влияния на систему корпоративного образования имеет огромное значение, которое принципиально меняет и стратегию, и тактику образования. Основоположниками теории поколений стали Н. Хоув и У. Штраус, сформулировавшие основные параметры концепции, и предложившие ставшее наиболее популярными определения и годы жизни.

Поколения X, Y, Z присутствуют сейчас в компании одномоментно. Конечно, поколение $Z$ только начинает выходить на рынок труда и формировать свой запрос на обучение, но массово в компании сейчас присутствуют поколения X и Ү. Система корпоративного образования во многих компаниях выстроена под запрос поколения Х. Для этого поколения характерны длинные и «вдумчивые» программы обучения, объемные и по знаниям, и по наполнению, простроенные и логичные. Это не значит, что для других поколений не нужна логика и простройка программ обучения, это просто означает, что структура программ требуется совершенно иная. Как отмечает при этом В. Пошехонова, люди старшего поколения в настоящее время обладают гораздо большим уровнем компьютерной грамотности, чем ранее [7, с. 14]. Прежде всего они достаточно широко пользуются соответствующим оборудованием в обычной жизни. Вторым важным фактором становится тот факт, что представители поколения $\mathrm{X}$ достаточно хорошо умеют использовать руководства и инструкции для обучения. Дело в данном случае не возрасте как таковом или развитости информационных или цифровых компетенций. Дело в смене парадигмы обучения. Как замечает С. Журихин, для поколения Ү характерен совершенно другой запрос на обучение [6]. Для поколения Y в процессе обучения характерен запрос на быстроту обучения, быстроту получения информации. А также быстроту отработки навыка или умения. Это запрос на короткие и быстрые программы с одной стороны. С другой стороны, поколение Ү демонстрирует запрос на реализацию концепции ЗА: получение любого контента в удобное для них время, в удобном для них формате. Для этого поколения характерен запрос на обучение в стиле Snack Learning и на геймофикацию программ обучения [6]. Такого рода запрос со стороны целевой аудитории заставляет компании не просто уходить в онлайн обучение, а использовать инструменты и технологии e-learning, мобильного обучения, дистанционного обучения. В этом случае существенно повышается роль самообразования, использование наставничества и менторинга. Эти тенденции отмечались и до COVID-19 пандемии, однако в настоящее время приобрели основополагающее значение.

Смена парадигмы обучения в контексте теории поколений связна еще и с цифровизации жизни и развитием технологий информационного общества. В связи с развитием информационного общества развиваются способы и средства коммуникаций. Их и технические, и коммуникационные возможности меняют не только коммуникационную и медийную среду, но и образовательные возможности. Среди наиболее важных цифр глобального отчета Digital 2020 по части распространения интернета в мире следует выделить следующие цифры: на январь 2019 общее количество пользователей Интернет в мире составляет 4,54 млрд. Также неуклонно растет аудитория пользователей социальных сетей. Аудитория пользователей социальных сетей на январь 2019 года достигла уже более 3,8 млрд. человек. На январь 2019 в мире было зафиксировано 5,19 млрд. пользователей мобильных телефонов [2]. Соответственно и система корпоративного образования должна двигаться вслед за своей целевой аудиторией. Именно с этими двумя факторами - развитием коммуникационных технологий и наличием нескольких поколений на рынке труда и объясняются фокусы изменений в системе корпоративного образования.

В этой связи важно отметить, что корпоративное образование сегодня - это система позволяющая быстро, гибко и результативно реагировать на изменения стратегии и операционной деятельности компании, и максимально быстро и качественно развивать необходимые функциональные или корпоративные компетенции сотрудников компании. Именно такими условиями в том числе обусловлена необходимость формирования новой модели корпоративного медиаобразования.

Безусловно сейчас будет меняться бизнес- модель организаций в сторону микширования онлайн и офлайн 
технологий работы и коммуникаций. Опыт локдауна не пройдет бесследно. Сегодняшний локдаун и глобальный экономический кризис выступают здесь в качестве не только как повод изменений, но и их катализатором, который затрагивают саму бизнес-модель.

Систему корпоративного обучения для компаний любого уровня безусловно также ждут принципиальные изменения, одним из таких изменений является формирование модели корпоративного медиаобразования.

Прежде всего это интеграционный подход к формированию самой системы корпоративного образования в целом, но медиаобразования в частности. И если до 2020 года крупные корпорации искали новые формы онлайн обучения, инвестируя достаточно крупные бюджеты в развитие дистанционного обучения, elearning, мобильное обучение и т.д. Теперь возможность дистанционного образования будут рассматривать и средние компании, и малый бизнес.

Принципы интеграционной модели корпоративного медиаобразования завтрашнего дня лежат в следующем. Bo-первых, это опора на смешанное обучение (blended education). Смешанное обучение - это сочетание традиционных форм обучения в классе с элементами дистанционного (электронного) обучения, в котором используются специальные информационные технологии, такие как компьютерная графика, аудио и видео, интерактивные элементы и т.д.[11, с. 29]. Процесс смешанного обучения представляет собой последовательность этапов традиционного обучения и электронного обучения, которые чередуются во времени, а также включает в себя элементы самостоятельного обучения. Расширение части онлайн и digital обучения, использование мобильного обучения не только позволяет оптимизировать бюджеты, но и обеспечить гибкость и быстроту получения и развития необходимых компетенций.

Вторым принципом интеграционной модели корпоративного медиаобразования является формирование единого образовательного пространства. Такой подход позволяет не просто использовать элементы управления знаниями в компании, а полномасштабно использовать систему управления знаниями. Единое образовательное пространство - это физическое окружение для учебной среды, место, где происходит обучение и обучение; внутреннее или наружное местоположение, реальное или виртуальное [11, с. 53]. Единое образовательное пространство позволяет не просто собрать воедино все необходимые образовательные материалы, но и выстроить преемственность образовательных программ, собрать воедино корпоративные знания, процедуры, кейсы. Для корпоративной модели медиаобразования именно формирование единого образовательного пространства является важной составляющей. С одной сто- роны система медиаобразования включена в систему корпоративных коммуникаций, с другой стороны одной из медиаобразовательных технологий являются лучшие практики компании и рынка, используемые в качестве кейсов для обучения. Поскольку традиционно привычные формы обучения как такового в настоящее время и технически, и ситуационно становятся все менее и менее востребованными, появляется необходимость в формировании единой корпоративной базы знаний. Такая корпоративная база знаний как часть системы управления знаниями компаниями сохраняет как локальные, так и глобальные лучшие решения и практики. Такой подход широко используется в PWC и Ernst\&Young например.

Третьим принципом интеграционной модели корпоративного медиаобразования является формат корпоративного университета. Не смотря на то, что как правило, корпоративный университет ассоциируется с крупными корпорациями, сейчас это далеко не так. Корпоративный университет в современном понимании является образовательным подразделением, призванным поддерживать стратегическое развитие компании и быть катализатором для его обновления путем обучения менеджеров и других сотрудников, а также путем создания, накопления и распространения передовых знаний внутри организации [12, с. 60].

И, наконец, четвертым принципом интеграционной модели системы корпоративного медиаобразования становится принцип комплаенс (compliance) или принцип сочетания\ соответствия. По сути, именно compliance подход позволяет в системе корпоративного образования в формате корпоративного университета учесть интересы всех заинтересованных сторон. Наиболее удобно реализовывать такой принцип становится возможным на основании стандарта ISO19600:2014.

Наиболее популярный в недавнем прошлом и наиболее затратный формат преподавания - аудиторные занятия - сегодня представляет собой лишь вершину большой пирамиды самых разнообразных современных методов обучения. Однако без аудиторных занятий достаточно сложно развить практические навыки многих компетенций.

Важно заметить, что операционная практика 2020 года для всех компаний показала большой провал в цифровой и медийно- информационной грамотности у сотрудников практически всех компаний, которые буквально в течении нескольких дней были вынуждены перейти на удаленный формат работы в онлайне.

Онлайн формат работы предполагает огромный объем информации, который буквально падает на сотрудника компании. Умение не просто работать с огромным массивом информацией (Big Data), но оценивать адек- 
ватность информации, ее правдивость и т.д. становится принципиально важной компетенцией. Это сфера медийно-информационной грамотности. Вторым важным фактором стала необходимость формирования цифровой грамотности. Умение работать в цифровой среде, знание программного обеспечения, умение работать на разных ресурсах является сейчас необходимым для результативной деятельности компании.

Такой фокус на медийно-информационную и цифровую грамотность крупные корпорации в рамках системы корпоративного образования стали реализовывать и в процессе локдауна. Например, компания Норникель уже запустила проект «Цифровой Норникель». Программа рассчитана на два года; ее первый этап стартовал в середине апреля, второй запланирован на сентябрь текущего года. Сформированный цикл программ «Цифровой «Норникель» позволит всем сотрудникам выбрать необходимые курсы в онлайн-обучении цифровой грамотности, развить соответствующие компетенции и повысить уровень квалификации [5].

Включение медийно-информационной и цифровой грамотности в структуру курсов корпоративного образования важно с нескольких сторон.

Прежде всего запуск таких программ в срочном порядке позволит быстро нарастить уровень медий- ных, информационных и цифровых компетенций для результативности работы в условиях удаленной работы и онлайн формата деятельности компаний. С другой стороны, компетенции медийно-информационной грамотности сейчас играют важную роль в корпоративных коммуникациях и формирования медийного имиджа организации. В рамках формирования медийного имиджа в современной медиасреде важны не только официальные коммуникации компании, но и личные медиаресурсы сотрудников. Контент, который они размещают в социальных сетях, например, напрямую влияют на медийный имидж компании. Например, скандал с неоднозначным комментарием в личном аккаунте бывшего PR-директора компании Леруа Мерлен стал для компании серьезным испытанием [3].

В заключении важно отметить, что система корпоративного образования не просто является одной из важнейших частей системы управления человеческим капиталом организации. В современных условиях это один из ключевых факторов влияния на качество человеческого капитала, а значит на эффективность системы управления в целом. Модель корпоративного медиаобразования, нацеленная на формирование медийно-информационной и цифровой грамотности, позволяет существенно влиять на конкурентную эффективность организации в современных условиях.

\section{ЛИТЕРАТУРА}

1. Берман Н.Д. К вопросу о цифровой грамотности // Russian Journal of Education and Psychology. 2017. №6-2, С. 35-38.

2. Интернет в России: статистика и тренды.// Электрон. дан. Режим доступа URL https://vc.ru/future/109699-internet-2020-v-rossii-i-mire-statistika-i-trendy. htm (дата обращения 27.08.2020)

3. Как пиар-директор «Леруа Мерлен» лишилась работы из-за скандала в «Фейсбуке».// Электрон. дан. Режим доступа URL https://www.bbc.com/russian/ news-44708103.htm (дата обращения 22.05.2020)

4. Медийно-информационная грамотность: определение. // Электрон. дан. Режим доступа URL https://iite.unesco.org/ru/mig.htm (дата обращения 30.08.2020)

5. «НОРНИКЕЛЬ»: цифровой рывок в условиях самоизоляции.// Электрон. дан. URL https://www.nornickel.ru/news-and-media/press-releases-and-news/ nornikel-tsifrovoy-ryvok-v-usloviyakh-samoizolyatsii.htm (дата обращения 22.05.2020)

6. Особенности обучения поколения Y.// Электрон. дан. Режим доступа URL https://zhurihin.ru/study_y (дата обращения 14.06.2020)

7. Пошехонова В.А. Образовательная гуманитарная технология цифрового поколения.// Педагогическое образование в России, № 5, 2018, С. 13-20.

8. Удаленная работа: организационные и технические решения.// Электрон. дан. Режим доступа URL https://www.tadviser.ru/index.php/ Статья: 06зор_ TAdviser_Удаленная_работа:_организационные_и_технические_решения.htm (дата обращения 29.08.2020)

9. Удаленная работа: технологии и опыт организации. /Конобевцев Ф.Д, Лаас Н.И, Гурова Е.И, Романова И.А. // Вестник ГУУ. 2019. №7. С. 9-17

10. An Executive's Guide to Returning Employees to the Workplace. // Электрон. дан. Режим доступа URL https://www.gartner.com/en/insights/coronavirus.htm (Дата обращения 27.08.2020)

11. Corporate Learning for the Digital World. Edited by Valery Katkalo, Martin Moehrle, Dmitry Volkov. — Moscow: Sberbank Corporate University, 2019,252 p.

12. Smolinska Olesia, Dzyubynska Khrystyna. The Concept of Cultural and Educational Space in Pedagogical Discourse. Journal of Vasyl Stefanyk Precarpathian National University. 2018. Vol. 5, No. 1. P. 55-64

(c) Ярных Вероника Игоревна (vyarnykh@gmail.com).

Журнал «Современная наука: актуальные проблемы теории и практики» 